\title{
Blood sugar response to glucagon in migraine
}

\author{
K. L. De SIlva, M. A. RON, AND JOHN PEARCE ${ }^{1}$ \\ From the Combined Neurological Service, Hull Royal Infirmary, Hull, \\ and the Institute of Psychiatry, Maudsley Hospital, Denmark Hill, London
}

SUMMARY The hyperglycaemic response to intramuscular glucagon was studied in 19 migraine subjects and 17 matched controls. Venous blood sugar 30 minutes after the injection, and the maximum rise from fasting levels, were significantly reduced in migraine subjects. This diminished sensitivity to the hyperglycaemic action of glucagon may be at least one factor in the hypoglycaemia unresponsiveness shown in migraine.

Migraine might perhaps be regarded as a reaction determined by a lowered threshold of central cerebral mechanisms, in combination with a wide range of external precipitating factors (Pearce, 1969, 1971a; Rao and Pearce, 1971). So far attempts to demonstrate or measure a central disorder of threshold have been unsuccessful, but the more precise delineation of external precipitating mechanisms and of endogenous biochemical anomalies susceptible to these triggers is important.

It is well known that in certain migraine subjects attacks can be precipitated by hunger and fasting (Critchley and Ferguson, 1933; Blau and Cumings, 1966; Pearce, 1971a). Migraine subjects also show a tendency towards a 'flat glucose tolerance curve' (Gray and Burtness, 1935; Wilkinson, 1949), but Pearce (1971b) showed that it is not hypoglycaemia per se which is responsible for precipitating migraine attacks in susceptible subjects. Rao and Pearce (1971) found that, during an extended standard insulin hypoglycaemia test, migraine subjects showed a hypoglycaemia unresponsiveness. This investigation also effectively excluded a defect of the corticotrophin-cortisol part of the hypothalamopituitary-adrenal axis, and one of the remaining possible explanations was a defect of hepatic glycogen breakdown. The present study aims to assess hepatic glycogenolysis by the glucagon test, in migraine and control subjects.

\footnotetext{
1 Requests for reprints: Dr. J. Pearce, Hull Royal Infirmary, Hull, $32 \mathrm{~J} 2$.
}

\section{METHODS}

Thirty-six volunteers, consisting of 19 migraine patients and 17 controls, were studied. The age range in both groups was 20 to 45 years. The migraine subjects consisted of 14 females and five males, and the controls consisted of 12 females and five males. The selection was weighted in favour of females because of their higher prevalence rate for migraine. The body weights were slightly less on average in the migraine group; this would if anything increase the hyperglycaemic effect of glucagon.

All subjects were fasted and requested to abstain from smoking from midnight. Venous blood samples were obtained through an indwelling heparinized cannula. The first blood sample was obtained immediately before the intramuscular injection of $1 \mathrm{mg}$ glucagon at 9.00 a.m. Further samples were then obtained at 30 minute intervals for two hours. Blood sugar was estimated by the Technicon auto-analyser method using alkaline-ferricyanide. Throughout the test the subjects were kept under continuous observation.

\section{RESULTS}

The results are summarized and the statistical significance of the differences between the two groups are given in the Table. At 30 minutes after the injection (at which point the maximal hyperglycaemic response to glucagon occurred in most subjects), a sharp separation occurred, the value for the migraine subjects being less than that of the controls. This difference is significant $(P<0.05)$. The maximal rise in blood sugar from the fasting level was also significantly lower in the migraine group $(\mathrm{P}<0.05)$. 
TABLE

GLUCAGON TEST-SUMMARY OF RESULTS

\begin{tabular}{|c|c|c|c|c|c|c|c|}
\hline & \multirow[t]{2}{*}{ Weight $(k g)$} & \multicolumn{6}{|c|}{ Venous blood sugar ( $\mathrm{mg} / 100 \mathrm{ml})}$. \\
\hline & & Fasting & $30 \mathrm{~min}$ & $60 \mathrm{~min}$ & $90 \min$ & $120 \min$ & $\underset{\text { rise }}{\text { Maximum }}$ \\
\hline $\begin{array}{l}\text { Controls }(17 \\
\text { Mean } \\
\text { SE }\end{array}$ & $\begin{array}{r}64 \cdot 1 \\
2 \cdot 2\end{array}$ & $\begin{array}{r}76 \cdot 7 \\
2.0\end{array}$ & $\begin{array}{r}121 \cdot 5 \\
5.8\end{array}$ & $\begin{array}{r}96 \cdot 4 \\
7 \cdot 3\end{array}$ & $\begin{array}{r}72 \cdot 7 \\
6 \cdot 0\end{array}$ & $\begin{array}{r}62 \cdot 7 \\
4 \cdot 1\end{array}$ & $\begin{array}{r}45 \cdot 7 \\
4 \cdot 6\end{array}$ \\
\hline $\begin{array}{l}\text { Migraine pat } \\
\text { Mean } \\
\text { SE }\end{array}$ & $\begin{array}{r}55 \cdot 5 \\
2 \cdot 4\end{array}$ & $\begin{array}{r}75 \cdot 6 \\
2.5\end{array}$ & $\begin{array}{r}108.9 \\
3.5\end{array}$ & $\begin{array}{r}91 \cdot 1 \\
3 \cdot 4\end{array}$ & $\begin{array}{r}70 \cdot 4 \\
3 \cdot 2\end{array}$ & $\begin{array}{r}63 \cdot 0 \\
3 \cdot 4\end{array}$ & $\begin{array}{r}36 \cdot 2 \\
3 \cdot 1\end{array}$ \\
\hline Significance & & NS & $\mathbf{P}<0.05$ & NS & NS & NS & $P<0.05$ \\
\hline
\end{tabular}

\section{DISCUSSION}

Because hypoglycaemia per se does not appear to be the factor responsible for migraine induced by fasting (Pearce, 1971b) it is necessary to look for a different cause. The hypoglycaemia unresponsiveness shown by an unselected group of migraine subjects (Rao and Pearce, 1971) may give a clue to this factor, and in any case requires explanation. Since the cortisol response to insulin induced hypoglycaemia and the metapyrone test were normal in these subjects, this phenomenon is not due to a defect of the hypothalamo-pituitary-adrenal axis and could be explained by:

1. A failure of other mechanisms which normally counteract hypoglycaemia-that is, inhibition or defective release of physiological insulin antagonists-notably, growth hormone, glucagon, and adrenaline.

2. Increased sensitivity at a tissue level to administered insulin.

The results of the present study indicate a defect in the normal hyperglycaemic response to glucagon and it is thus probable that this is at least one factor in the hypoglycaemia unresponsiveness shown by migraine subjects. This is likely to be due to a defect in hepatic glycogenolysis, which is the means by which glucagon produces its hyperglycaemic effect, but this is only one of the complex actions of this hormone.

The possible relation of this finding to the production of the migraine attack in such subjects on fasting is speculative. One possibility is that if migraine subjects show a physiological resistance to the action of glucagon (which we have not shown here) this could cause an overproduction of this hormone by 'negative feed back' in an effort to combat the hypoglycaemia. This hypothetical over-production could result in other effects which might precipitate migraine. For instance, it is known that glucagon, in addition to its hyperglycaemic effect, has a pronounced lipolytic effect (Hagen, 1961; Vaughan et al., 1964; Lefebvre and Luyckx, 1969), and this may act as the trigger for the migraine attack. Hockaday et al. $(1971,1973)$ showed that during fasting, plasma free fatty acids rose very much higher in subjects who developed a migraine attack than in those who did not, and this may be relevant. Tests of plasma glucagon, insulin, and growth hormone responses to physiological 'stresses' are required further to elucidate this problem.

Migraine appears to be a pattern of clinical features occurring in response to a lowered central threshold, triggered by differing external and endogenous factors. One such factor in a subgroup of migraine patients is an anomaly of carbohydrate metabolism. There is evidence for a mechanism with insulin-like action which (1) depresses the blood glucose response to a glucose load ; (2) is responsible for hypoglycaemia unresponsiveness after exogenous insulin; and (3) lowers the hyperglycaemic effect of administered glucagon. There is no evidence that this mechanism is directly related to migraine symptoms, nor is it clear if it is a primary phenomenon or one secondary to other metabolic anomalies 
such as those shown in fat breakdown occurring in hunger prone subjects and in diabetes mellitus.

\section{REFERENCES}

Blau, J. N., and Cumings, J. N. (1966). Methods of precipitating and preventing some migraine attacks. British Medical Journal, 2, 1242-1243.

Critchley, M., and Ferguson, F. R. (1933). Migraine. Lancet, $1,123-126$ and $182-187$.

Gray, P. A., and Burtness, H. I. (1935). Hypoglycemic headache. Endocrinology, 19, 549-560.

Hagen, J. H. (1961). Effect of glucagon on the metabolism of adipose tissue. Journal of Biological Chemistry, 236, 10231027.

Hockaday, J. M., Williamson, D. H., and Whitty, C. W. M. (1971). Blood-glucose levels and fatty-acid metabolism in migraine related to fasting. Lancet, 1, 1153-1156.

Hockaday, J. M., Williamson, D. H., and Alberti, G. (1973) Migraine. In Background to Migraine. Fifth Migraine Symposium, Heinemann: London. (In press.)
Lefebvre, P., and Luyckx, A. (1969). Lipolytic action of glucagon in vitro and in vivo. In Physiopathology of Adipose Tissue, pp. 257-268. Edited by J. Vague. Excerpta Medica Foundation: Amsterdam.

Pearce, J. (1969). Migraine: Clinical Features, Mechanisms and Management. Thomas: Springfield, Ill.

Pearce, J. (1971a). General review. Some aetiological factors in migraine. In Background to Migraine, pp. 1-7. Fourth Migraine Symposium, 1970. Edited by J. N. Cumings. Heinemann: London.

Pearce, J. (1971b). Insulin induced hypoglycaemia in migraine. Journal of Neurology, Neurosurgery, and Psychiatry, 34, 154-156.

Rao, N. S., and Pearce, J. (1971). Hypothalamic-pituitaryadrenal axis studies in migraine with special reference to insulin sensitivity. Brain, 94, 289-298.

Vaughan, M., Berger, J. E., and Steinberg, D. (1964). Hormone-sensitive lipase and monoglyceride lipase activities in adipose tissue. Journal of Biological Chemistry, 239, 401-409.

Wilkinson, C. F., Jr. (1949). Recurrent migranoid headaches associated with spontaneous hypoglycemia. American Journal of Medical Science, 218, 209-212. 